\title{
Uso de las redes sociales en la Administración pú- blica gallega: ¿una técnica de marketing 2.0?
}

\author{
José SIXTO GARCÍA ${ }^{1}$ \\ Universidad de Santiago de Compostela
}

\begin{abstract}
RESUMEN:
En este artículo se estudia el uso que hace de las redes sociales la Administración pública gallega: el gobierno autonómico, los Ayuntamientos de las siete grandes ciudades y las Diputaciones Provinciales. Se analizan las modalidades comunicativas en red que las instituciones emplean en su comunicación con los públicos, atendiendo a los entornos interactivos de la web 2.0 y especialmente a las redes sociales. La metodología utilizada se fundamenta en una encuesta de respuestas cerradas, en la observación participante y en fichas de análisis de contenidos. Los resultados describen el modelo de comunicación aplicado, los espacios con presencia y participación, las modalidades de comunicación y marketing ejecutadas, la frecuencia de uso, la interacción con el usuario y el establecimiento de canales bidireccionales entre fuente y audiencias. A partir de estos datos se examina también el posible uso de las redes sociales como técnica de marketing 2.0.
\end{abstract}

PALABRAS CLAVE: Redes sociales; instituciones públicas; interacción; marketing 2.0.

TITLE: Use of the social networks in the public Galician Administration: an instrument of marketing 2.0?

\begin{abstract}
In this article we study the use of the social networks by the public Galician Administration: the autonomous government, the Town halls of seven cities and the County councils. We analyze the communicative modalities on line used in the communication with the public ones, attending especially to the interactive environments of the web 2.0 and to the social networks. The used methodology is based on a survey of closed answers, on the observation and on cards of analysis of contents. The results describe the model of communication applied, the spaces with presence and participation, the modalities of communication and marketing executed, the frequency of use, the interaction with the user and the establishment of bidirectional channels between issuer and audience. From this information we also examine the possible utilization of the social networks as an instrument of marketing 2.0.
\end{abstract}

KEY WORDS: Social networks; public institutions; interaction; marketing 2.0.

\section{Diseño de la investigación, materiales y método}

La investigación que presentamos es de carácter fundamentalmente exploratorio, puesto que analiza el uso que las instituciones públicas gallegas hacen de las redes sociales y su consecuente empleo como técnica de marketing 2.0. Formulado este

1 Doctor en Periodismo. Departamento de Ciencias de la Comunicación.

jose.sixto.garcia@gmail.com 
objetivo general, definimos los objetivos específicos que pretendimos conseguir con el trabajo:

1. Identificar los tipos de soportes en que las instituciones públicas gallegas ejercen comunicación en la red, tanto en formatos tradicionales como en los propios de la web 2.0.

2. Valorar la importancia que las instituciones públicas gallegas conceden a Internet, a los medios sociales en general y a las redes sociales en particular para comunicarse con sus públicos.

3. Observar las prácticas comunicativas implementadas en las redes sociales y definir y comprobar si la estrategia seguida responde a técnicas de operaciones de marketing (público).

Identificamos, en primer lugar, los elementos que componían ese conjunto que denominamos instituciones públicas gallegas. Es decir, concretamos la muestra de estudio, esto es, el subconjunto de elementos que pertenecen a ese conjunto definido, partiendo de la premisa de que pocas veces es posible medir toda la población ${ }^{2}$. Sin embargo, entendemos que en este caso concreto para investigar el conjunto de la comunicación institucional gallega era necesario investigar todas las unidades que lo componían $^{3}$. La muestra es probabilística, ya que todos los elementos tuvieron la misma posibilidad de ser escogidos, pero al tiempo elegimos todos los elementos del conjunto, por lo que en lugar de muestra debemos referirnos a conjunto total.

En consecuencia, si el conjunto de la población es $N$ y la muestra es $n, N=n$, puesto que conjunto y muestra coinciden, lo que asegura un margen de error igual a 0 . Para el cálculo del tamaño de la muestra que se requiere para la representación de la población, consultamos también el programa STATS ${ }^{\circledR}$.

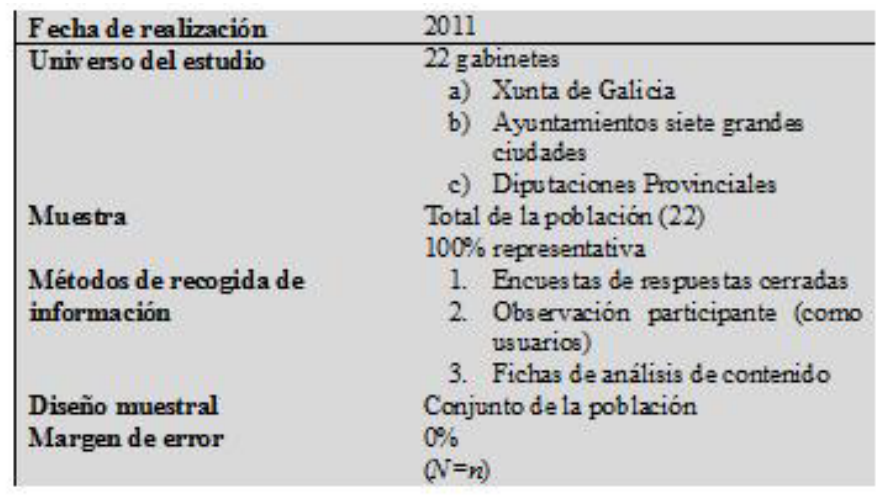

Fig. 1. Ficha técnica de la investigación

Fuente: elaboración propia

${ }^{2}$ Hernández, R.; Fernández, C. y Baptista, P. (2007): Fundamentos de metodología de la investigación (adaptación de la primera edición mexicana), Madrid, McGraw Hill, 159-160.

${ }^{3}$ Se desecharon las instituciones locales, ya que por paralelismo presupuestario y de recursos humanos no existe equivalencia comparativa entre ambos factores. 
El conjunto a estudiar está formado por 22 unidades que se corresponden con las instituciones de Gobierno en Galicia: la Xunta de Galicia y sus diez consellerías, los Ayuntamientos de las siete grandes ciudades y las cuatro Diputaciones Provinciales. La Xunta de Galicia y cada una de las consellerías fueron analizadas individualmente, pues cada una practica una política comunicativa diferente, funcionan como una especie de organismos autónomos y no existe coincidencia entre las estrategias seguidas por unas y otras. Puede comprobarse la distribución gráfica en la siguiente tabla:

\begin{tabular}{|c|c|c|}
\hline \multicolumn{2}{|c|}{ Subconjunto de instituciones } & Identificación individualizada \\
\hline 1 & \multirow{9}{*}{ Xunta de Galicia } & Xunta de Galicia \\
\hline 2 & & $\begin{array}{l}\text { Conselleria de Presidencia, Administracións Piblicas e } \\
\text { Xustiza }\end{array}$ \\
\hline 3 & & Conselleria de Facenda \\
\hline 4 & & $\begin{array}{l}\text { Conselleria de Medio Ambiente, Territorio e } \\
\text { Infraestruturas }\end{array}$ \\
\hline 5 & & Conselleria de Economia e Industria \\
\hline 6 & & Conselleria de Educación e Ordenación Universitaria \\
\hline 7 & & Conselleria de Sanidade \\
\hline 8 & & Conselleria de Cultura e Turismo \\
\hline 9 & & Conselleria de Traballo e Benestar \\
\hline $\begin{array}{l}10 \\
11 \\
12\end{array}$ & \multirow{7}{*}{$\begin{array}{l}\text { Ayuntamientos de las } \\
\text { siete ciudades principales }\end{array}$} & $\begin{array}{l}\text { Conselleria de Medio Rural } \\
\text { Conselleria do Mar } \\
\text { A Connña }\end{array}$ \\
\hline 13 & & Santiago de Compostela \\
\hline 14 & & Ferrol \\
\hline 15 & & Lugo \\
\hline 16 & & Ovrense \\
\hline 17 & & Pontevedra \\
\hline 18 & & Vigo \\
\hline 19 & \multirow[b]{2}{*}{ Diputaciones provinciales } & A Corvña \\
\hline $\begin{array}{l}20 \\
21 \\
22\end{array}$ & & $\begin{array}{l}\text { Lugo } \\
\text { Ourense } \\
\text { Pontevedra }\end{array}$ \\
\hline
\end{tabular}

Fig. 2. Distribución de la muestra (conjunto) de estudio

Fuente: elaboración propia

Definidos el conjunto de estudio y los objetivos, abordamos los métodos de investigación para poder satisfacer nuestros propósitos y dar respuesta a las preguntas de investigación con que partíamos: ¿las instituciones públicas gallegas emplean las redes sociales para comunicarse con las audiencias? ¿Qué prácticas comunicativas desempeñan en los entornos $2.0 ?$ ¿Responden a estrategias de marketing (público)?

Para poder obtener los datos que nos permitiesen despejar estos interrogantes, empleamos tres técnicas de investigación distintas, dos de indagación cuantitativa y otra de indagación cualitativa: 
a) Métodos cuantitativos: (1) una encuesta de respuestas cerradas realizada a los jefes de los gabinetes de comunicación de las respectivas instituciones sobre la utilización de Internet en general y de las redes sociales en particular en la comunicación con los públicos, en cuanto a soportes y plataformas empleadas, frecuencia de uso y prácticas ejecutadas. La encuesta se realizó por teléfono y correo electrónico en función de la elección de cada responsable y su validez fue pre-testada antes de proceder a la interrogación masiva. (2) El análisis de contenido y aplicaciones de los diferentes sitios sociales en que las instituciones manifestaron actividad se realizó mediante fichas de vaciado de contenido diseñadas para tal finalidad y adaptadas a las particularidades de cada una de las redes sociales.

b) Método cualitativo: simulación de la observación participante en el sentido de usuarios de las redes sociales en que las instituciones ejercen actividad para observar, analizar y describir los modelos utilizados, la calidad de los servicios y la variedad comparativa entre las ofertas.

En el caso de la encuesta, para minimizar el error de respuesta (respuestas imprecisas), empleamos para la medición una escala de valoración de grados, inspirada en el modelo de escala de Likert ${ }^{4}$, donde 0 representa la valoración mínima y 10 la máxima, siendo 5 el nivel mínimo de estimación positiva. Una vez obtenidos los datos resultantes de las encuestas, procedimos a su almacenaje y tratamiento en una base de datos elaborada en SPSS PASW 18 Statistic para su posterior interpretación.

Con respecto a los instrumentos empleados en la observación participante, las fichas de análisis y vaciado se elaboraron de forma que permitiesen la obtención de datos referentes a la descripción de la estrategia comunicativa general, a los niveles de interactividad conseguida y a la implementación de prácticas propias del marketing viral.

4 La escala de Likert es una escala psicométrica comúnmente utilizada en cuestionarios, que posibilita las valoraciones en función del nivel de acuerdo o desacuerdo con una declaración, un elemento, un ítem o, en su caso, un reactivo. Es decir, consiste en un conjunto de ítems presentados en forma de afirmaciones o juicios ante los que se pide la reacción del sujeto, eligiendo uno de los cinco puntos de la escala (Hernández, Fernández e Baptista, 2007):

(1) Muy de acuerdo

(2) De acuerdo

(3) Ni de acuerdo, ni en desacuerdo

(4) En desacuerdo

(5) Muy en desacuerdo

A veces, se acorta o incrementa el número de categorías, sobre todo cuando los responsables potenciales tienen una capacidad limitada de discriminación o muy amplia. En este sentido, 1 significaría discordancia total y 4 concordancia total, por ejemplo (Malhotra, 1999). El método fue desarrollo por Rensis Likert a principios de la década de 1930, pero ofrece un enfoque vigente y bastante popularizado. 


\section{Discusión: el fenómeno de la viralidad a través de las redes sociales}

Las redes sociales sirven fundamentalmente para conectar a las personas entre si $^{5}$, de tal forma que son «el entretejido formado por las relaciones sociales que, desde los diferentes ámbitos de vida y con diferente grado de significación, vinculan a un sujeto con otro» ${ }^{6}$. Su crecimiento ha sido espectacular en los últimos cinco años y hoy en día redes sociales como Facebook cuentan con más de 700 millones de usuarios en todo el mundo.

Conviene recordar que el concepto de red social en inglés (social network) ya había sido acuñado en 1954 por J.A. Barnes para describir una estructura social de nudos que son en general personas u organizaciones, de tal forma que una red social representa las relaciones entre personas, grupos u organizaciones. Evidentemente Barnes se refería a las redes físicas y no a las virtuales, aunque la principal diferencia entre unas y otras es fundamentalmente el tamaño, puesto que mientras que el tamaño máximo de una red física no suele superar las 150 personas, las redes sociales en Internet pueden albergar a varios miles de miembros, a pesar de que la fortaleza del nexo sea inferior.

Las redes sociales tienen su origen y posterior desarrollo en la Teoría de los Seis Grados de Separación, según la que toda la población del planeta está conectada a través de no más de seis personas. La teoría fue inicialmente propuesta por el húngaro Frigyes Karinthy en 1929 y se basa en las denominadas chains o cadenas, un concepto asentado en la idea de que el número de conocidos crece exponencialmente con la suma de enlaces en la cadena.

De esta manera, con un pequeño número de enlaces el conjunto de conocidos abarcaría a la totalidad de la población humana. La teoría, recogida también en el libro Six Degrees: The Science of a Connected Age del sociólogo Duncan Watts ${ }^{7}$, intenta demostrar, por tanto, que es posible acceder a cualquier persona con tan solo un máximo de seis saltos. Cada persona conoce de media -entre amigos, familiares o compañeros del trabajo o escuela- a unas 100 personas. Si cada uno de esos amigos o conocidos próximos se relaciona a su vez con otras 100 personas, cualquier persona podría enviar un mensaje a 10.000 personas más por medio de sus contactos. Esos 10.000 individuos son contactos de segundo nivel, es decir, que el individuo no conoce pero que puede conocer fácilmente a través de los que sí conoce. Si esos 10.000 conocen a otros 100 , la red se ampliaría a 1.000 .000 de personas conectadas en el tercer nivel, a 100.000.000 en el cuarto, a 10.000.000.000 en el quinto y a 1.000.000.000.000 en el sexto nivel. En seis pasos y con las tecnologías disponibles se podría enviar un mensaje a cualquier persona del planeta.

\footnotetext{
5 SixTO, J. (2011): «La red social Tuenti. Análisis del modelo de comunicación y de la estrategia de marketing», Telos. Cuadernos de Comunicación e Innovación, 89, 139-145.

6 NAVARRO, S. (2004): Redes Sociales y construcción comunitaria, Madrid, CCS, 47.

7 WatT, D. J. (2002): Six Degrees: The Science of a Connected Age, Nueva York, W. W. Norton \& Company, Inc.
} 
En la práctica real encontramos, sin embargo, que el número de contactos del segundo nivel es sustancialmente menor a 10.000 puesto que es usual tener amigos comunes en las redes sociales, aparte de apreciar que cuantos más pasos sea necesario dar, más alejada será la conexión entre dos usuarios y, en consecuencia, más difícil y despreciable la comunicación, aunque en las redes virtuales este inconveniente es inferior al patentado en las redes físicas. De todos modos, es necesario poner de manifiesto que las relaciones sociales virtuales no sustituyen a la comunicación física u off the line, ya que cada una de ellas tiene sus momentos y no son sustitutivas, sino complementarias. No se trata de comunicarse solo virtualmente, sino de comunicarse más y por canales diferentes y variados, lo que, por otra parte, aumenta la potencialidad viral del mensaje, que puede ser distribuido no solo por la fuente emisora, sino también por los propios receptores, en un paralelismo con el antiquísimo boca a boca.

Los estudios enmarcados en la investigación social como el de Dunbar, Gamble y Gowlet ${ }^{8}$-el primero de ellos director del Instituto de Antropología Evolutiva de Oxford- han establecido en 150 el número máximo de relaciones personales que un individuo puede establecer y gestionar de forma directa. No obstante, esa posibilidad aumenta de forma exponencial gracias a las nuevas tecnologías de la información y de la comunicación, de tal forma que una persona puede tener miles de relaciones a través de las redes e incluso formar parte de varias diferentes. De hecho, la media está establecida en 1,7 redes, según The Cocktail Analysis ${ }^{9}$. En este sentido, las herramientas informáticas o de software social operan en tres ámbitos para potenciar la eficacia de las redes sociales ${ }^{10}$ :

1. La gestión de conocimiento compartido, por ejemplo en las comunidades de blogs.

2. La integración de comunidades, como en el caso deFriendster.

3. La cooperación, como ocurre en Wikipedia.

\section{Resultados de la investigación}

\subsection{Comunicación institucional en la red: entornos tradicionales y entornos sociales}

En la actualidad todas las instituciones públicas del Gobierno gallego (100\%) Xunta de Galicia, Diputaciones Provinciales y Ayuntamientos de las siete grandes ciudades- emplean Internet para comunicarse con el público. Los niveles de inten-

\footnotetext{
${ }^{8}$ Dunbar, R.; Gamble, C. y Gowlet, R. (2009): Social Brain, Distributed Mind, Nueva York, Oxford University Press.

${ }^{9}$ Citado en CAMPOS, F. (2009): «Os grupos mediáticos poñen o ollo na economía de afiliación e a colaboración das redes sociais», Observatorio (OBS) Journal, 11, 57-73.

${ }^{10}$ San Millán, E.; Medrano, Ma L. y Blanco, F. (2008): «Social Media Marketing, Redes Sociales y Metaversos», en Castro, E. y Díaz, J. (coords.), Universidad, Sociedad y Mercados Globales, Madrid, Asociación Española de Dirección y Economía de la Empresa (AEDEM), 353-366.
} 
sidad de utilización y las tipologías de uso varían, pero como punto de partida constatamos el uso de la red como canal de comunicación a través de los portales corporativos de las propias instituciones, empleados en la totalidad de casos.

A los portales corporativos les sigue la comunicación institucional en sitios web ajenos, que son utilizados por siete de cada diez instituciones $(77,27 \%)$, sobresaliendo el caso de las Diputaciones, pues todas ellas recurren a esta modalidad. En un tercer puesto encontramos la comunicación ejercida en portales y redes sociales, a los que acuden casi tres cuartos de las instituciones gallegas $(72,72 \%)$, aunque la diferencia con la comunicación ejercida en las webs corporativas y en otras ajenas es notable, lo que refleja preferencia por la comunicación de carácter unidireccional, en la que el emisor crea y difunde el mensaje, limitando así las posibilidades interactivas de los receptores y menguando la comunicación usuario-institución.

Google Maps como localizador de la entidad $(36,36 \%)$ y los enlaces patrocinados $(31,81 \%)$-de nuevo dos formas de comunicación con limitadas posibilidades de participación del usuario- constituyen el cuarto y quinto puesto respectivamente, como se observa en la siguiente figura:

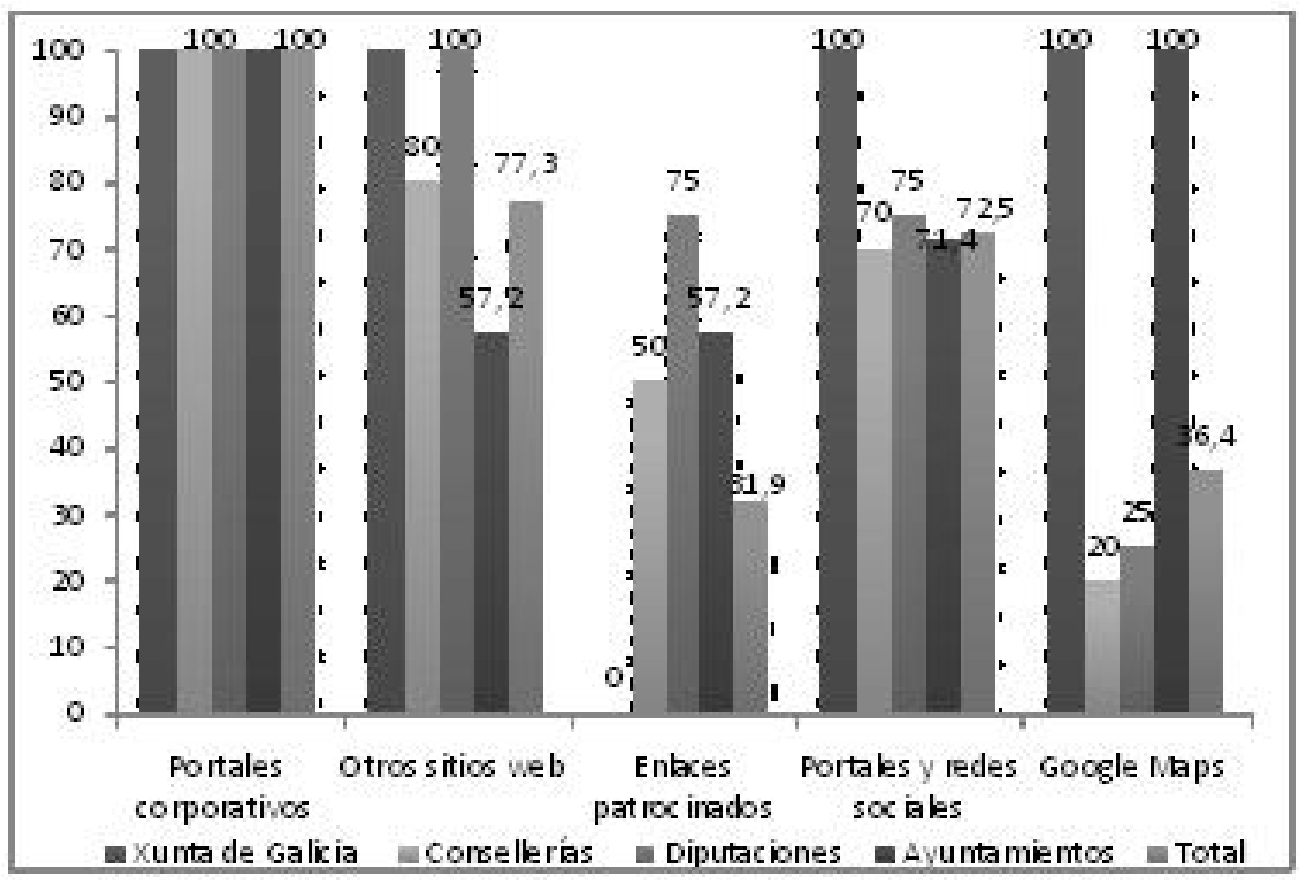

Fig. 3. Tipos de portales en los que las instituciones ejercen comunicación ${ }^{11}$

Fuente: elaboración propia

${ }^{11}$ La suma de porcentajes es superior a 100 porque se permitió la respuesta múltiple. Ocurre así en lo sucesivo. 
De entre las opciones comunicativas que permiten los portales sociales, las redes sociales son la opción preferida por la mayoría de las instituciones para acercar su producto a los usuarios, de manera que ocho de cada diez organismos $(81,25 \%)$ que utilizan algún medio social para comunicarse utilizan alguna red social, aunque esto no suponga una equivalencia con un uso masivo y generalizado, ya que son empleadas por seis de cada diez instituciones del conjunto total $(59,09 \%)$.

Por tanto, la presencia de las instituciones gallegas en los diversos medios sociales se sitúa en el $72,72 \%$, esto es, solo 13,63 puntos por encima de la intromisión en redes sociales $(59,09 \%)$, lo que evidencia que la práctica totalidad de los sitios sociales vinculados a órganos de Gobierno en Galicia son redes sociales:

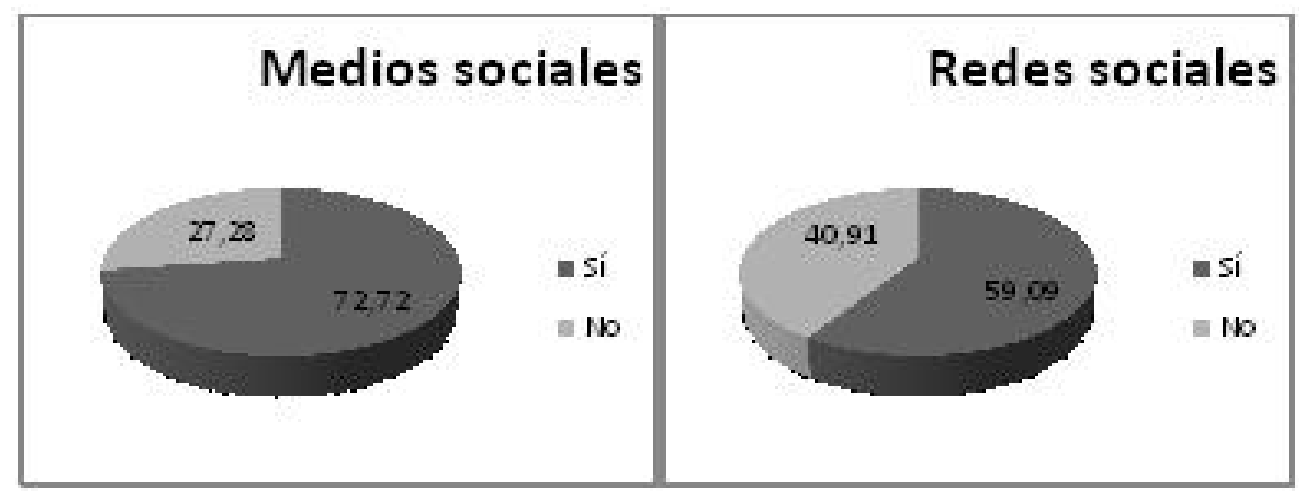

Figs. 4 y 5. Presencia de las instituciones gallegas en medios sociales y redes sociales Fuente: elaboración propia

Les siguen los blogs $(36,36 \%)$ y los videoblogs $(18,18 \%)$, mientras que otras alternativas como los fotoblogs $(4,54 \%)$, los microblogs $(4,54 \%)$ o los mundos virtuales $(4,54 \%)$ apenas alcanzan representación: 


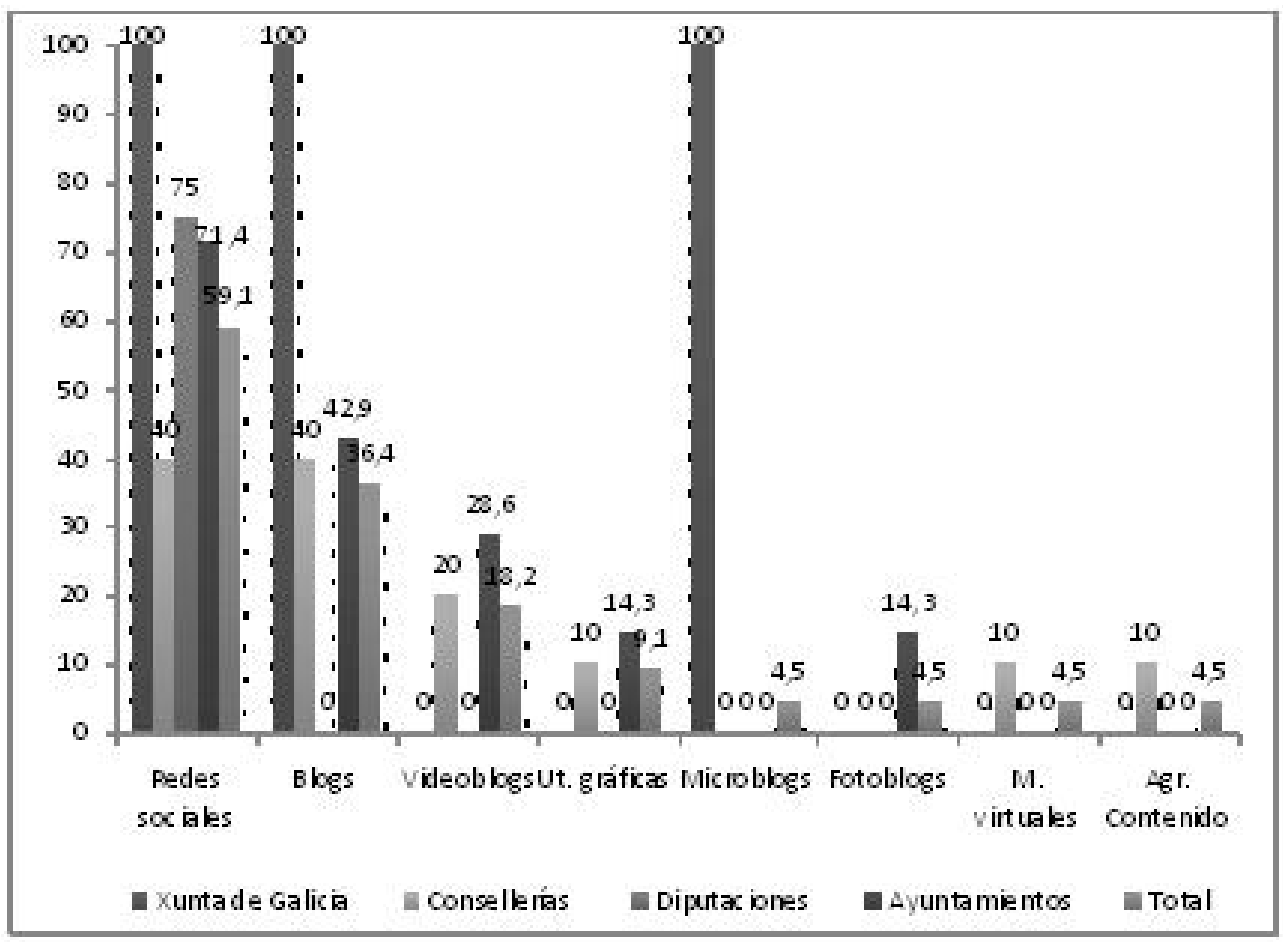

Fig. 6. Tipos de medios sociales empleados por las instituciones gallegas Fuente: elaboración propia

Por el contrario, no todas las redes tienen la misma acogida entre las instituciones. Todos los organismos públicos con presencia en redes sociales usan la red mayoritaria en España y en el mundo, Facebook (100\%). La siguiente por orden de elección es YouTube $(46,15 \%)$, lo que demuestra preferencia por:

a) Las redes sociales de carácter generalista y de ocio.

b) Las redes que cuentan con un gran número de usuarios tanto en Galicia como en el conjunto del Estado, así como a nivel mundial.

c) Las redes que permiten el uso de materiales audiovisuales.

Otras redes que también responden a estas características -Twitter $(38,46 \%)$, Tuenti (15,38\%) y Myspace (14,28\%)- completan la lista de las cinco redes sociales que son utilizadas por las instituciones gallegas en su comunicación pública. Así pues, apreciamos que de las diez redes sociales de mayor audiencia en Espa$\tilde{n a}^{12}$, la mitad (50\%) son rehusadas, como refleja la siguiente figura:

${ }^{12}$ Nos referimos -en orden decreciente- a: Google, Facebook, YouTube, Tuenti, Twitter, Badoo, Myspace, Fotolog, LinkedIn y Adultfriendfinder. 


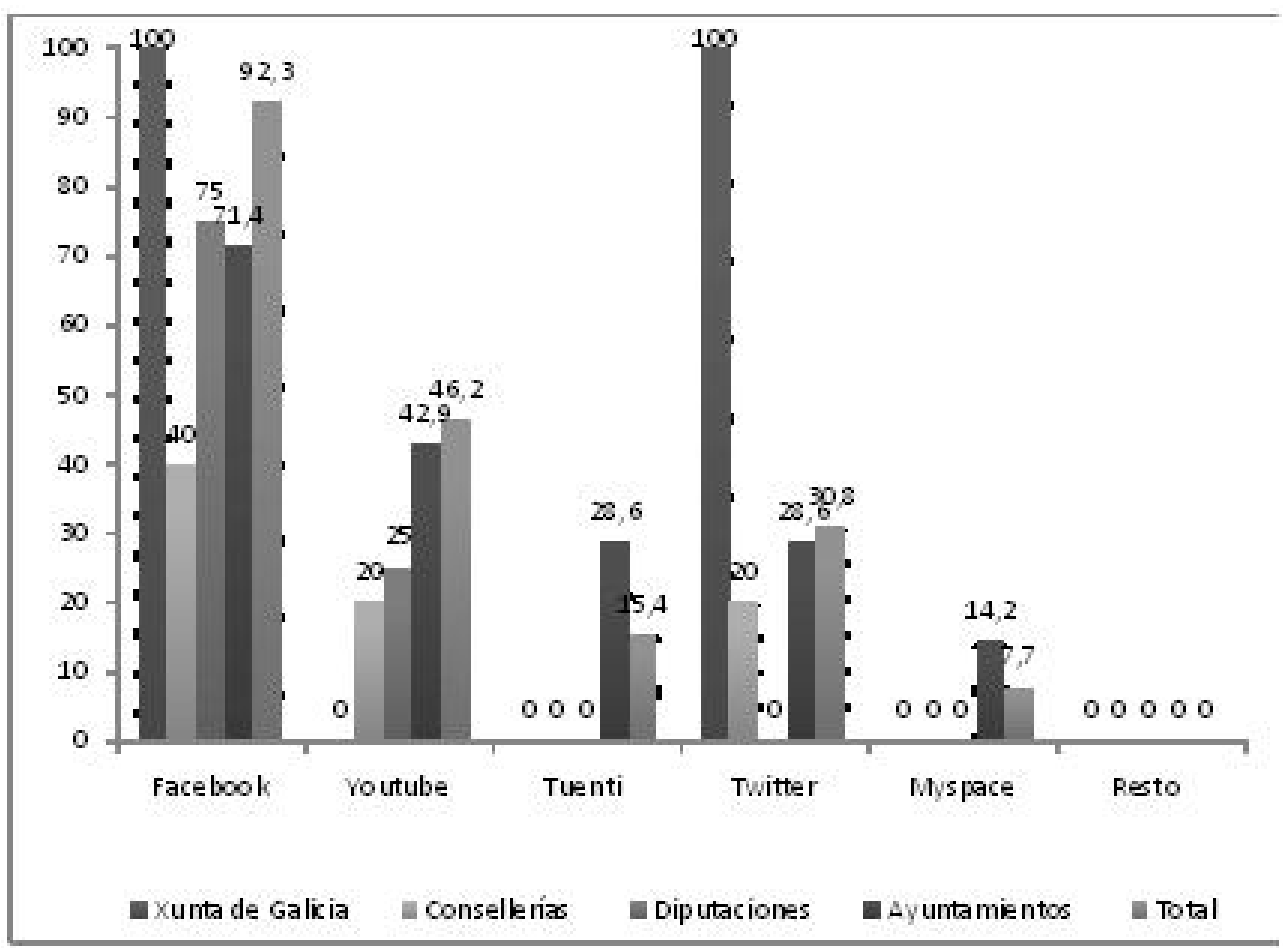

Fig. 7. Redes sociales usadas en la comunicación pública gallega Fuente: elaboración propia

En cambio, cuatro de cada diez instituciones $(40,91 \%)$ todavía no utilizan ninguna red social. Entre los motivos que señalan para no hacerlo, encontramos que la mayoría $(44,44 \%)$ considera que el público de su institución no es activo en las redes sociales, mientras que casi un cuarto $(22,22 \%)$ estima que la posibilidad de que los usuarios participen en la elaboración y difusión de los contenidos resta control y veracidad a lo que la fuente quiere transmitir. Otros achacan factores como la falta de medios materiales para poner en marcha una política de comunicación en medios sociales $(11,11 \%)$ y otros que las redes son inapropiadas para comunicar información institucional (11,11\%): 


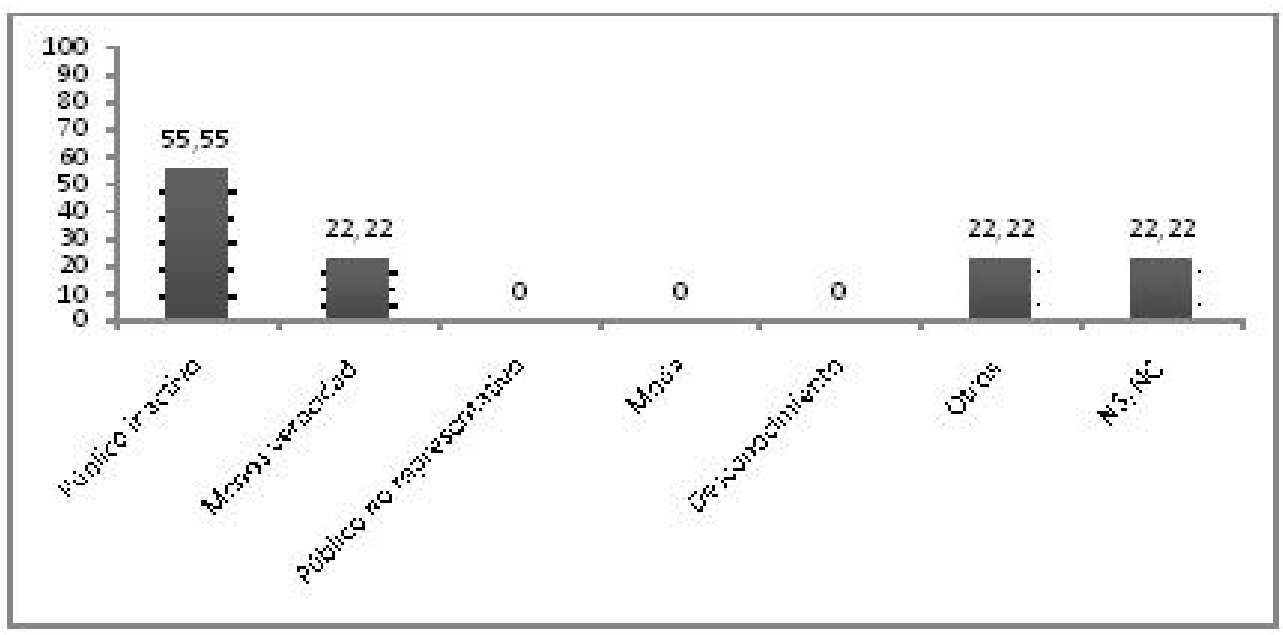

Fig. 8 Motivos para rechazar el uso de redes sociales en la comunicación pública Fuente: elaboración propia

De las instituciones gallegas con presencia en medios sociales $(59,09 \%)$, más de la mitad usan un blog $(61,53 \%)$, aunque es cierto que tres de cada cuatro $(75 \%)$ combinan la comunicación en blog con la comunicación en red social, de modo que solo la consellería de Educación e Ordenación Universitaria y la consellería de Medio Rural utilizan el blog en exclusividad, representado ambas el $25 \%$ de instituciones que utilizan medios sociales para comunicarse con las audiencias. En el conjunto de instituciones las que emplean blog constituyen el $36,36 \%$, mientras que las que lo usan en exclusividad suponen el 9,09\% del total del conjunto gallego.

La mayoría de los que apuestan por la combinación de blog y red social destacan que la especificidad del formato blog permite explicar los hechos de manera más pormenorizada (60\%), a la vez que el $40 \%$ atribuye su uso a una decisión personal de los políticos y un quinto (20\%) a que su actualización es más sencilla que en el caso de las redes sociales. No obstante, nadie confirma que el hecho de que su auge sea anterior al de las redes suponga un impedimento para dar el cambio.

\subsection{Importancia de la comunicación digital}

Cuando les pedimos a las instituciones gallegas que valorasen la importancia concedida a Internet en general y a los medios sociales en particular en su comunicación cotidiana nos encontramos con que la estimación que hacen de Internet es altamente satisfactoria: 9,44 puntos sobre 10, mientras que la moda se sitúa en 10 puntos. Sin embargo, la puntuación desciende con respecto a los medios sociales, que alcanzan 7,19 puntos, aunque las redes sociales son mejor valoradas: 7,32 puntos de media y 8 puntos de moda. 
En este sentido, se observa como los organismos estudiados conceden gran importancia a Internet para comunicarse con los usuarios, aunque apuestan más por fórmulas de comunicación unidireccional que limitan la participación del receptor, mientras que los medios sociales como los blogs, los fotoblogs o las wikis son peor valorados, a pesar de que dentro de este subconjunto las redes sociales presentan una mejor acogida y los responsables de comunicación estiman que su importancia en el aspecto comunicativo es mayor:

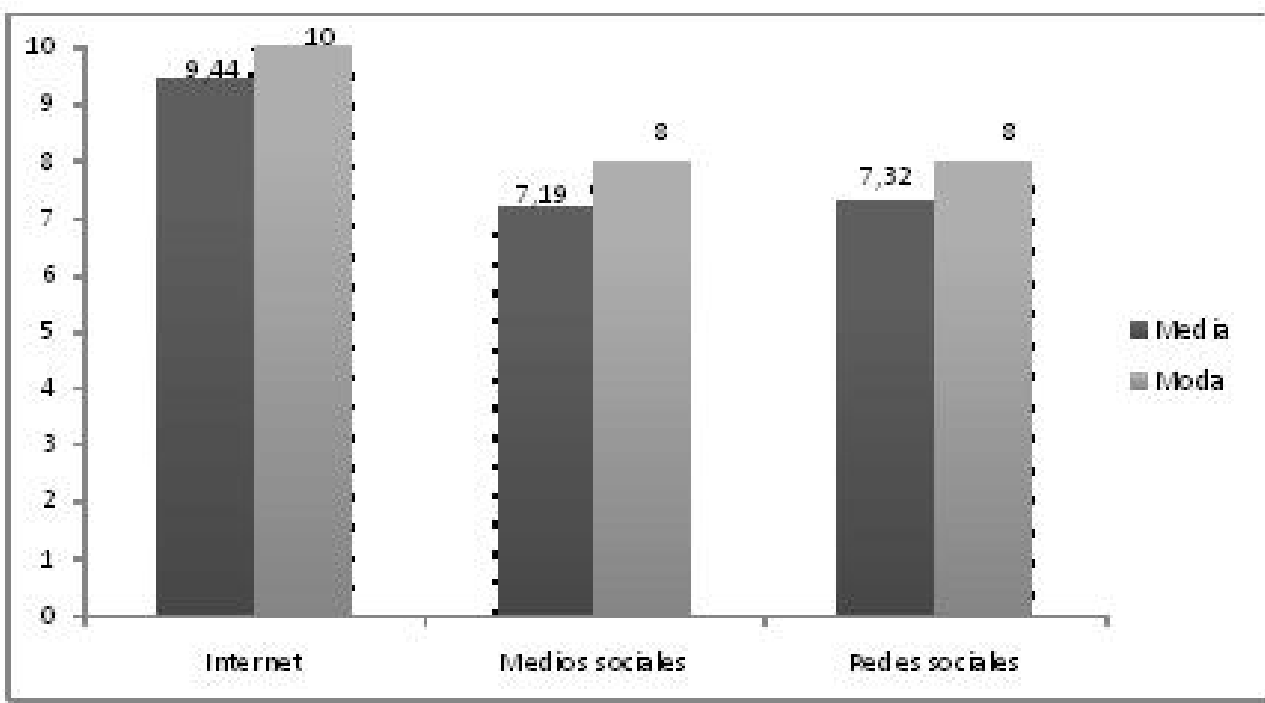

Fig. 9. Media y moda de la valoración de Internet, medios sociales y redes sociales Fuente: elaboración propia

\subsection{Redes sociales como técnica de marketing 2.0}

De las instituciones que utilizan las redes sociales como instrumento de comunicación con el público, todas $(100 \%)$ aseguran hacerlo por la capacidad que ofrecen para que los usuarios difundan la información a otros usuarios, es decir, por el factor intrínseco de las técnicas de marketing viral, que aplicado en este campo significa que los responsables de comunicación encuentran en las redes sociales no solo la posibilidad de que los usuarios consuman lo que producen, sino que además difundan entre su red de contactos aquellos productos que son de su interés. Desde este punto de vista, se observa el interés de la fuente emisora en ser recibida, pero también en ser distribuida, y además de forma gratuita. El propósito y la intención están claros, pero más adelante veremos cómo los mecanismos y las prácticas que efectúan para conseguirlo no son las más adecuadas.

También en este sentido, otra de las utilidades que destacan de las redes sociales es el número de usuarios con los que cuentan $(69,23 \%)$, así como la posibilidad que 
ofrecen para poder segmentar el público al que dirigirse (76,92\%), lo que entronca con la opción de realizar una comunicación más personalizada o one to one (38,46\%), aunque los datos dan a entender que prefieren realizar una comunicación más homogénea y que luego sean los propios usuarios quienes la distribuyan en función de la afinidad temática e ideológica:

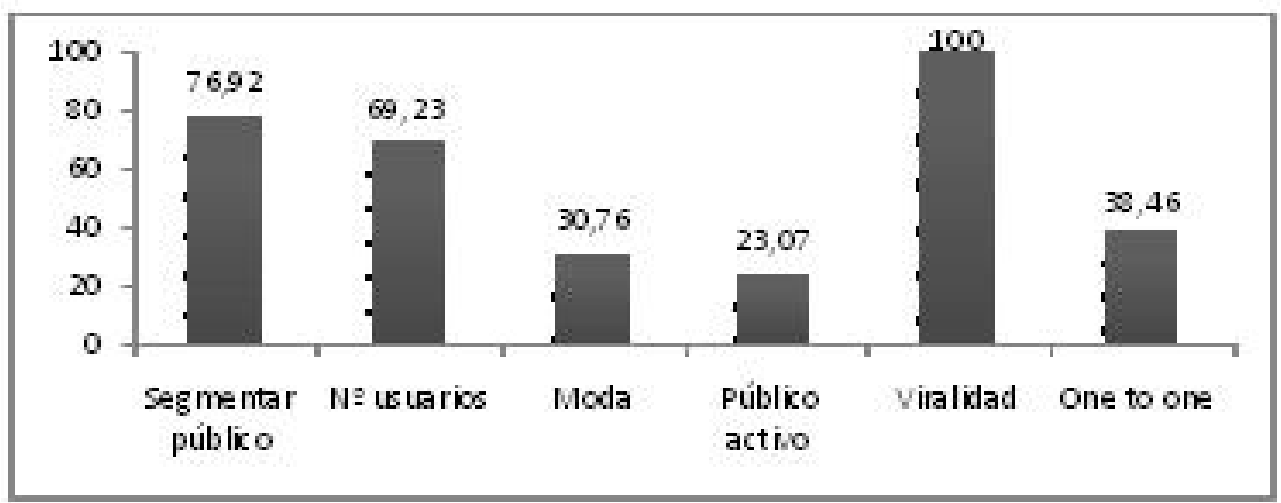

Fig. 10. Utilidad de las redes sociales como instrumento de comunicación con los públicos Fuente: elaboración propia

Con respecto a las prácticas comunicativas ejecutadas en las redes sociales, ocho de cada diez instituciones $(84,61 \%)$ las utilizan para promocionar eventos que crean como usuarios y difunden entre la red de contactos esperando una propagación contagiosa, lo que conecta directamente con la causa principal señalada como incentivo para registrarse en una red social: la potencialidad viral de estas plataformas. El factor es especialmente notorio en el caso de las Diputaciones, donde la totalidad $(100 \%)$ se decanta por esta opción preferente, aunque tampoco podemos olvidar la creación de perfiles -tanto en el caso de las Diputaciones (66,66\%) como en el conjunto total $(69,23 \%)$ - y grupos -también mayoritariamente en el caso de las Diputaciones $(66,66 \%)$ y en la mitad de los casos totales $(53,84 \%)$ : 


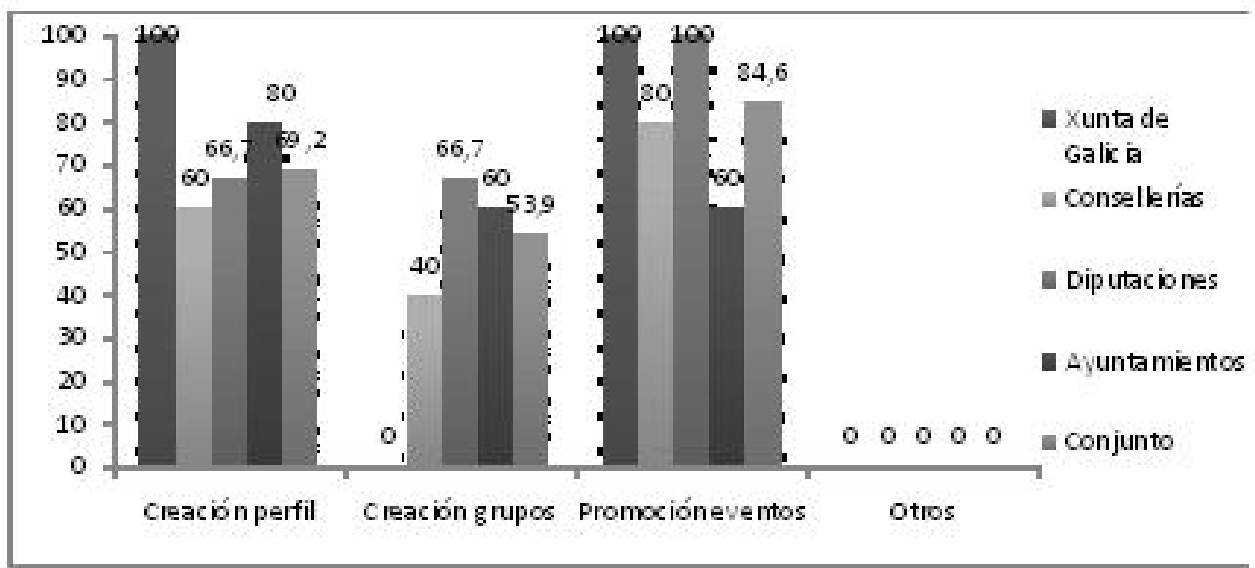

Fig. 11. Prácticas comunicativas implementadas en las redes sociales

Fuente: elaboración propia

En función de la interpretación anterior, podemos afirmar que todas las instituciones gallegas que usan las redes sociales emplean los servicios, las aplicaciones y las plataformas que estas ofrecen de manera gratuita a todos los usuarios, tales como la creación de perfiles, grupos o la promoción de eventos. Se trata, pues, de una modalidad comunicativa que no requiere inversión por parte de quien la promueve y que exige la práctica del marketing viral para su éxito, en el sentido de que tan importante como la creación de este tipo de identidades son su difusión, expansión y recepción por los públicos a los que van dirigidas.

Aun así, existe un 23,07\% de instituciones que reconoce que, aparte de los servicios ofrecidos gratuitamente, han contratado algún servicio no gratuito a través de alguna empresa externa $(15,38 \%)$ o mediante el contacto que permite la propia red $(7,69 \%)$. Fruto de la observación participante, se comprobó que esta opción se refería a la creación de canales en YouTube o a la contratación de tweets promocionados.

En cuanto al tipo de información que difunden, las instituciones gallegas utilizan las redes sociales para divulgar todo tipo de actividades desarrolladas por ellas mismas $(92,30 \%)$, aunque no correspondan estrictamente ni con actos festivos $(53,84 \%)$ ni con congresos o eventos científicos $(23,07 \%)$. En cambio, lo que más sorprende de la interpretación gráfica que sigue es que los diferentes organismos utilizan las redes para publicar cualquier tipo de información, excepto la que consideran institucional, que solo hace uno de cada tres $(30,76 \%)$. Llama la atención el caso de las consellerías de la Xunta de Galicia, ya que la transmisión de este tipo de información es nula $(0 \%)$ y se restringe, pues, a los mecanismos tradicionales, donde la participación del receptor es mucho más limitada y los niveles de interactividad descienden o incluso desaparecen. A pesar de que en el gabinete de la Secretaría Xeral de Medios de la Xunta de Galicia ocurre justo lo contrario, la ten- 
dencia se reduce, por tanto, a utilizar las redes sociales para dar información de cualquier tipo, excepto la puramente institucional u oficial:

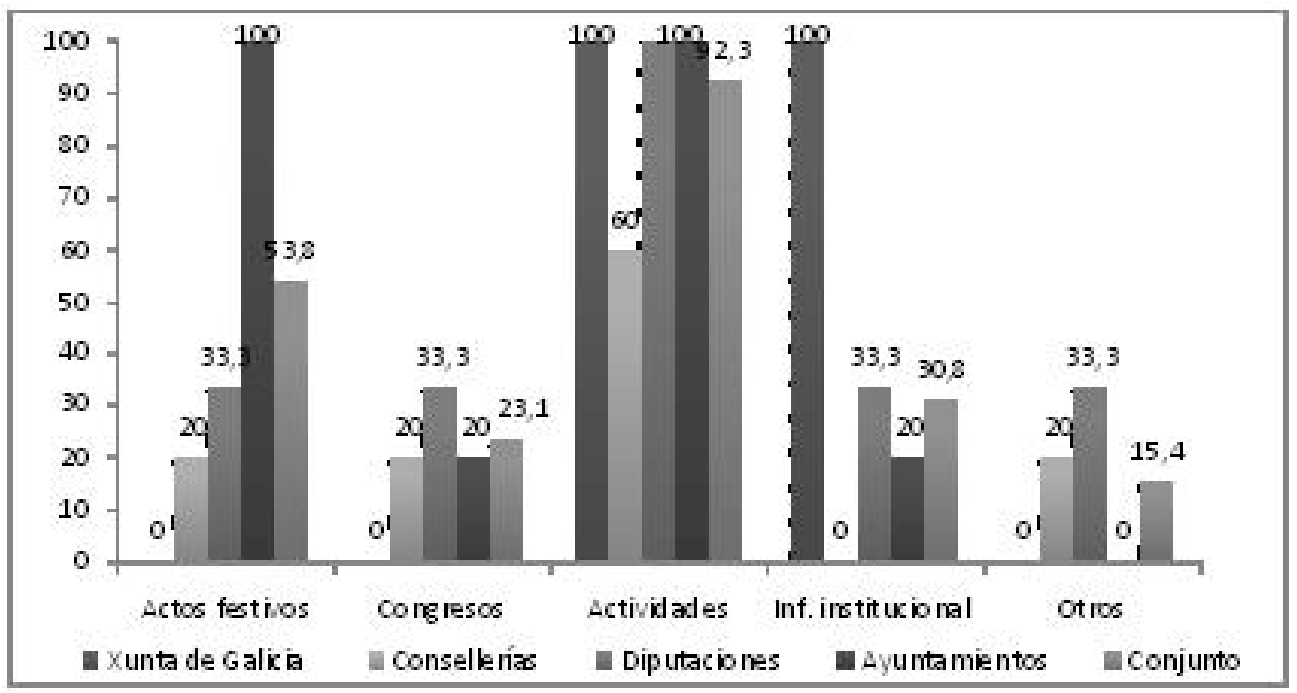

Fig. 12. Tipo de información difundida en las redes sociales

Fuente: elaboración propia

Más de la mitad de las instituciones con participación en redes sociales crean perfiles $(61,53 \%)$ : de ellas el 33,33\% cuentan exclusivamente con un perfil institucional, el $44,44 \%$ con un perfil de un político y el $22,22 \%$ restante con una combinación de ambos. Sin embargo, la intención con que realizan esta tarea varía y, en este sentido, tres de cada cuatro $(77,77 \%)$ la atribuyen al acercamiento al público en general, mientras que menos de un cuarto $(22,22 \%)$ reconocen intereses políticos en esta creación y, en consecuencia, el acercamiento a posibles votantes. Apreciamos, por lo tanto, una clara inclinación hacia el marketing político en lugar de hacia el marketing público. Interesa más lo que dice el político que lo dice la institución.

En esta línea, también la mayoría (66,66\%) identifican que el motivo de la creación de perfiles de personajes políticos se debe a una razón de proximidad con el público, pues entienden que las redes sociales constituyen un canal de comunicación más directo que las webs corporativas, sin que lleguen a sustituirlas, sino que se utilizan como complemento. Esto ratifica el éxito de los perfiles en las instituciones más vinculadas con los públicos locales como son las Diputaciones y los Ayuntamientos, mientras que acusa un ligero descenso en el caso de las consellerías y una ausencia total en la Xunta de Galicia, donde los perfiles del presidente dicen que no son gestionados desde el gabinete de comunicación.

La frecuencia de actualización de los contenidos es otro de los factores clave que permiten el éxito del marketing 2.0. No todas las instituciones gallegas con participación activa en las redes sociales manifiestan la misma frecuencia en la 
actualización de los contenidos que difunden. Algo más de un tercio (38,46\%) los actualiza en un periodo temporal comprendido entre uno y cuatro días, mientras que una de cada tres $(30,76 \%)$ patenta una actualización diaria, lo que supone que la mayoría de las instituciones $(69,24 \%)$ actualiza los contenidos en un margen temporal inferior a los cinco días.

Los porcentajes son similares con respecto a la frecuencia de comprobación de la participación de la audiencia (interacción) en los perfiles. En este caso, existe un empate entre los periodos de examen entre uno y cuatro días $(46,15 \%)$ y la comprobación diaria (46,15\%), por lo que podemos afirmar que nueve de cada diez instituciones $(92,30 \%)$ registran unan frecuencia de exploración inferior a los cinco días.

Apreciamos, por lo tanto, cierto paralelismo entre la frecuencia de actualización de contenidos y la frecuencia de comprobación de participación de las audiencias, lo que permite deducir la práctica rutinaria de acceso a los perfiles sociales para su actualización y examen de las respuestas del público a los contenidos publicados con anterioridad o bien para encontrar inquietudes, demandas, opiniones o comentarios que cualquier usuario pudiese haber dejado en el perfil institucional.

A medida que se agranda la esfera receptora, los niveles de interactividad descienden y, en consecuencia, las potencialidades y capacidades comunicativas de los entornos 2.0 en general y de las redes sociales en particular también disminuyen. Los datos pueden estudiarse más pormenorizadamente en las siguientes figuras:

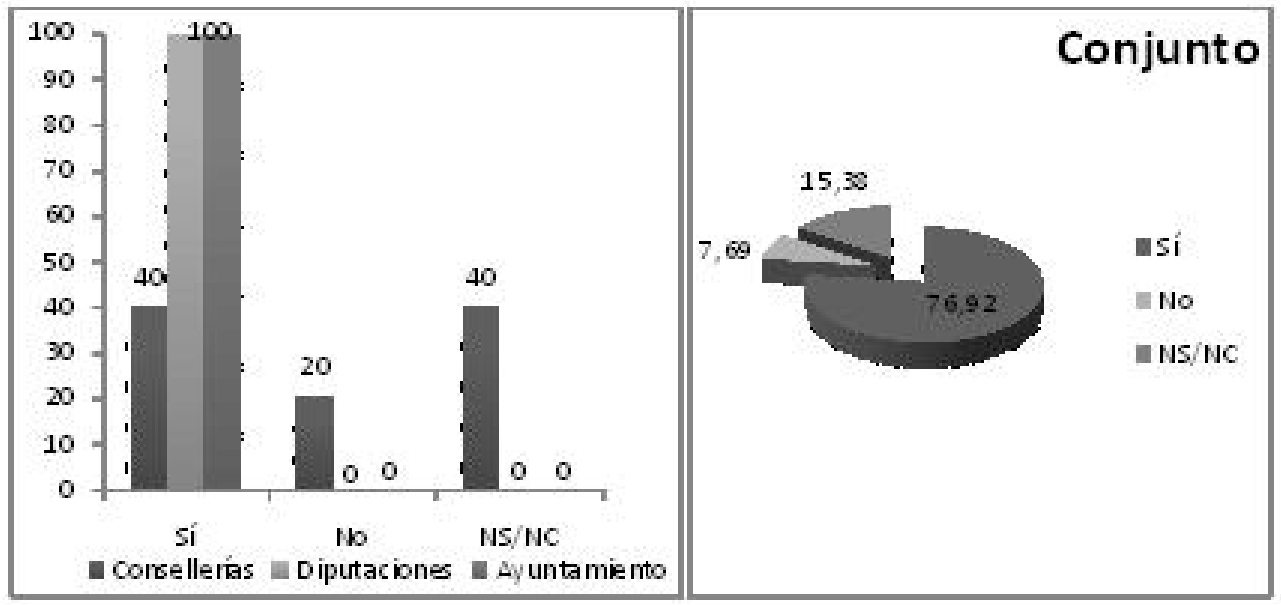

Figs. 13 y 14. Nivel de respuesta a la participación de la audiencia Fuente: elaboración propia

En lo que respecta a las prácticas comunicativas desarrolladas en cada una de las redes predominan las ejecutadas en Facebook de manera gratuita. Así, seis de cada diez instituciones $(61,53 \%)$ que están en Facebook crean perfiles y grupos, mientras que cuatro de cada diez $(46,15 \%)$ aprovechan para publicar eventos. 
Las siguientes modalidades más usadas las encontramos en YouTube y Twitter, de forma que más de un tercio de los organismos $(38,46 \%)$ suben a la red vídeos de actos o eventos institucionales y otros tantos $(38,46 \%)$ optan por el formato de mensaje corto y directo que ofrece Twitter. Con todo, existe también un 15,38\% de instituciones que reconoce que graban vídeos ex profeso para colgarlos en YouTube y otro $7,69 \%$ que afirma aprovechar vídeos ya subidos publicarlos en su portal corporativo. La cuarta red preferida es Tuenti y en ella la modalidad comunicativa elegida es la creación de eventos, aunque su uso es limitado (15,38\%), pero superior a la conformación de grupos en Myspace, que solo utiliza el 7,69\% de las instituciones públicas gallegas.

Las modalidades gratuitas se erigen, pues, como las preferidas, a pesar de que también se registran datos de contrataciones de opciones de pago. Es el caso de anuncios en Facebook (7,69\%) o de los tweets promocionados (15,38\%), siendo, entonces, Twitter la red más seleccionada dentro de esta modalidad.

\section{Conclusiones finales}

Todas las instituciones públicas gallegas estudiadas tienen presencia en Internet por medio de sus respectivas páginas web corporativas desde la última mitad de la década de 1990. Sin embargo, estas presencias se caracterizan de forma mayoritaria por establecer un tipo de comunicación unidireccional institución-receptor, donde la interactividad entre ambos elementos registra niveles muy bajos y donde lo único que parece importar es la información difundida por la fuente, desmereciendo la opinión y la participación ciudadanas.

Las instituciones gallegas otorgan 9,44 puntos sobre 10 a la importancia concedida a Internet en la esfera comunicativa, 7,32 puntos a las redes sociales y 7,19 puntos a los medios o sitios sociales en general. La primera interpretación que se extrae de estos datos es, pues, la preferencia por Internet como canal de comunicación unidireccional, puesto que reducen la valoración positiva al referirse a los entornos sociales -que implican bidireccionalidad e interacción con el usuario-, aunque de entre estos escenarios las redes sociales son las mejor valoradas.

El $72,72 \%$ de las instituciones públicas gallegas se interesa por estos entornos sociales propios de la web $2.0 \mathrm{y}$, de hecho, seis de cada diez $(59,09 \%)$ tienen presencia en redes sociales. Por otra parte, tres de cada cuatro instituciones gallegas (75\%) con presencia en contextos sociales combinan la presencia en blog y en red social. En el conjunto total de instituciones las que emplean blog suponen el $36,36 \%$, mientras que las que lo usan en exclusiva se proscriben al 9,09\%.

En cualquier caso, la investigación nos permite concluir que las instituciones gallegas eligen las redes sociales como un instrumento o plataforma más en la que practicar comunicación, aunque esta práctica se refiera básicamente a la presencia y/o registro en redes y no tanto a una participación activa y constante en las mis- 
mas. Existe, por tanto, cierta tendencia a incorporarse a estos espacios sociales, pero en la que prima la presencia sobre la participación real. Los criterios de selección de redes se corresponden siempre con los mismos parámetros: redes de carácter generalista y de ocio, que cuentan con un gran número de usuarios tanto en Galicia como en España (también en el resto del mundo) y redes que permiten el uso de materiales audiovisuales, señaladamente fotografías.

Para seleccionar las redes en las que participar el principal factor que utilizan es la edad de los usuarios, señalado por el $84,61 \%$ de las instituciones. Facebook es la red social por antonomasia, porque todas las instituciones que usan redes sociales están en esta red y también porque es la que cuenta con mayor media de seguidores. De todas maneras, las presencias se disputan entre otras cuatro redes más, que son por orden de preferencia: YouTube, Twitter, Tuenti y Myspace. Las prácticas implementadas se corresponden habitualmente con modalidades que pueden ser efectuadas de forma gratuita.

Detrás de la decisión de utilizar redes sociales en la comunicación pública reside uno de los grandes fundamentos del marketing actual: el uso de técnicas virales. Todas las instituciones justifican la participación en redes sociales por la capacidad que ofrecen para que los usuarios difundan o expandan la información a otros contactos, de modo que los usuarios no solo actuarían como receptores de contenidos, sino también como distribuidores e incluso creadores. De igual modo, siete de cada diez $(69,23 \%)$ señalan la posibilidad de segmentar el público al que dirigirse, en el sentido de realizar una comunicación por afinidad y, por tanto, con más posibilidades de propagación.

Esta intención de realizar una comunicación expansiva por afinidad se reproduce también en que la creación de eventos sea la práctica comunicativa más recurrida en las redes sociales. No obstante, solo cuatro de cada diez instituciones (46,15\%) comprueba a diario si registran participación de los usuarios y, mediante el vaciado de las fichas de análisis, comprobamos que el 78,57\% de las contribuciones de los usuarios en el muro de Facebook no eran contestadas.

Así pues, las potencialidades que ofrecen las redes sociales están poco explotadas por las instituciones públicas gallegas: son pocas las que usan redes sociales, las que las usan se registran en pocas y emplean las mínimas aplicaciones y servicios, se decantan por las de carácter generalista y los servicios gratuitos, y el establecimiento de la comunicación reproduce modelos propios del sistema 1.0, donde existe baja o nula bidireccionalidad, escasa interacción y participación del usuario y donde parece que importa más la presencia que la participación activa. El resultado es un bajo nivel de seguimiento por parte del público y, por tanto, la interactividad conseguida también es baja, lo que significa que las redes no se utilizan de manera correcta como una técnica de marketing $2.0 \mathrm{y}$, en consecuencia, su impacto en las audiencias es poco provechoso. 


\section{Referencias bibliográficas}

CAMpos, F. (2009): «Os grupos mediáticos poñen o ollo na economía de afiliación e a colaboración das redes sociais», Observatorio (OBS) Journal, 11, 57-73.

Dunbar, R.; Gamble, C. y Gowlet, R. (2009): Social Brain, Distributed Mind, Nueva York, Oxford University Press.

HERnÁNDEZ, R.; FERNÁNDEZ, C. y BAPTISTA, P. (2007): Fundamentos de metodología de la investigación (adaptación de la primera edición mexicana), Madrid, McGraw Hill.

Malhotra, N. K. (1999): Pesquisa de marketing: Uma Orientação Aplicada, São Paulo, Bookman.

NAVARRO, S. (2004): Redes Sociales y construcción comunitaria, Madrid, CCS.

San Millán, E.; Medrano, Ma L. y Blanco, F. (2008): "Social Media Marketing, Redes Sociales y Metaversos», en Castro, E. y Díaz, J. (coords.), Universidad, Sociedad y Mercados Globales, Madrid, Asociación Española de Dirección y Economía de la Empresa (AEDEM), 353-366.

SIXTO, J. (2011): «La red social Tuenti. Análisis del modelo de comunicación y de la estrategia de marketing», Telos. Cuadernos de Comunicación e Innovación, 89, 139-145.

WatTs, D. J. (2002): Six Degrees: The Science of a Connected Age, Nueva York, W. W. Norton \& Company, Inc.

Recibido: 7 de febrero de 2012

Aceptado: 13 de noviembre de 2012 